\title{
Anatomia comparativa de folhas e caules de Axonopus scoparius (Flügge) Kuhlm. e Axonopus fissifolius (Raddi) Kuhlm. (Poaceae) ${ }^{1}$
}

\author{
LENIR M. SILVA ${ }^{2,4}$ e YEDO ALQUINI ${ }^{3}$
}

(recebido: 7 de novembro de 2001; aceito: 12 de fevereiro de 2003)

\begin{abstract}
Comparative anatomy of leaves and stems of Axonopus scoparius (Flügge) Kuhlm. and Axonopus fissifolius (Raddi) Kuhlm. (Poaceae)). Several species in the genus Axonopus are commonly used as forage milk cattle to feed in southern Brazil. However, little is known about the anatomy of these plants. In this work, the structural features of leaves and stems of Axonopus scoparius (Flügge) Kuhlm. and A. fissifolius (Raddi) Kuhlm. are described. The samples were collected in Itajaí, SC and processed for light and scanning electron microscopy histological studies. The Kranz structure was found in both species. The species could be distinguished by the presence of bulliform cells in the leaf blade upper epidermis of A. fissifolius and the absence of these cells in A. scoparius and by the presence of unicellular macrohairs in the leaf blade upper epidermis of A. scoparius and the absence of these strutures in A. fissifolius.
\end{abstract}

Key words - Axonopus fissifolius, Axonopus scoparius, forage, Kranz, plant anatomy

RESUMO - (Anatomia comparativa de folhas e caules de Axonopus scoparius (Flügge) Kuhlm. e Axonopus fissifolius (Raddi) Kuhlm. (Poaceae)). Muitas espécies do gênero Axonopus são utilizadas como forrageiras de corte e pastejo no sul do Brasil. Contudo, pouco é conhecido sobre a anatomia dessas plantas. No presente trabalho foram descritas as características estruturais de folhas e caules das espécies Axonopus scoparius (Flügge) Kuhlm. e A. fissifolius (Raddi) Kuhlm. As amostras foram coletadas em Itajaí, SC e processadas para estudo histológico ao microscópio de luz e eletrônico de varredura. A estrutura Kranz foi evidenciada em ambas espécies. As espécies distinguem-se pela presença de células buliformes na epiderme da face adaxial da lâmina foliar de A. fissifolius e pela ausência destas células em A. scoparius e pela presença de tricomas longos, unicelulares na epiderme da face adaxial da lâmina foliar de A. scoparius e pela ausência destas estruturas em A. fissifolius.

Palavras-chave - Anatomia vegetal, Axonopus fissifolius, Axonopus scoparius, forrageira, Kranz

\section{Introdução}

O gênero Axonopus Beauvois é cultivado representativamente na região do Vale do Itajaí, SC. As espécies Axonopus scoparius (Flügge) Kuhlm. e A. fissifolius (Raddi) Kuhlm. são gramíneas tropicais nativas (Dedecca, 1956) utilizadas, respectivamente, como forrageiras de corte e pastejo para a bovinocultura de leite.

Poucos trabalhos com enfoque anatômico abordam espécies do gênero Axonopus. A clássica obra de Metcalfe (1960), que trata da anatomia de gramíneas, não inclui a descrição desse gênero. Anton (1986) descreve algumas características das lâminas foliares de ambas as espécies, porém não há descrição sobre bainha foliar e caules.

\footnotetext{
1. Parte da dissertação de mestrado de L.M. Silva, UFPR.

2. CEFET/PR, Unidade de Pato Branco, Via do Conhecimento, km 01, 85501-970 Pato Branco, PR, Brasil.

3. Universidade Federal do Paraná, Departamento de Botânica, Caixa Postal 19031, 81531-970 Curitiba, PR, Brasil.

4. Autor para correspondência: lebotanica@brturbo.com
}

Ambas as espécies pertencem à subfamília Panicoideae do grupo das Poaceae (Reyna \& Davila 1995). A. scoparius é uma planta perene, cespitosa, de aproximadamente $1,5 \mathrm{~m}$ de altura, de origem exótica, natural do México, amplamente difundida pelo cultivo, principalmente em regiões tropicais. A espécie A. fissifolius é perene, cespitosa, podendo ou não apresentar estolhos. Os colmos variam de 15 a $120 \mathrm{~cm}$ de altura sendo simples ou, às vezes, ramosos perto da base (Smith et al. 1982).

Deschamps (1994) concluiu que a espécie A. scoparius apresenta boa qualidade em função dos elevados valores de digestibilidade in vitro da matéria orgânica, estando estes resultados relacionados com a organização estrutural da espécie.

Estudos de anatomia vegetal, aplicados a área de nutrição animal, têm demonstrado o quanto podem ser úteis na solução de problemas. Rodella et al. (1984) estabeleceram comparações anatômicas quantitativas entre gramíneas forrageiras e concluíram que as características anatômicas da folha podem fornecer indicativos sobre o potencial de digestibilidade da celulose. Akin (1979) afirmou que o uso de técnicas microscópicas para avaliar a digestibilidade das 
forragens é um excelente meio para ajudar na elucidação dos fatores que afetam a degradação das forragens pelos microrganismos ruminais.

No presente trabalho efetuou-se a descrição da organização estrutural da lâmina e da bainha foliares e caule, destacando-se as diferenças encontradas entre as espécies.

\section{Material e métodos}

Os exemplares de Axonopus scoparius e A. fissifolius utilizados se encontram registrados no herbário UPCB da Universidade Federal do Paraná - Setor de Ciências Biológicas, sob os números 30313, 30314, 30315, 30316, 30317 e 30318.

As espécies encontravam-se estabelecidas em parcelas homogêneas de $10 \times 25 \mathrm{~m}$ na Estação Experimental da EPAGRI (Empresa Catarinense de Pesquisa e Extensão Agropecuária), em Itajaí, SC. A coleta de folhas completamente expandidas ocorreu em janeiro de 1997 e obedeceu o padrão descrito abaixo:

- para lâminas e bainhas foram retiradas amostras da porção mediana da terceira folha, contando a partir da folha bandeira; - para caules foram retiradas amostras da porção mediana do entrenó localizado imediatamente acima da inserção das folhas supramencionadas.

As amostras foram fixadas em FAA $70 \%$ por aproximadamente $48 \mathrm{~h}$ e posteriormente armazenadas em álcool 70\% (Johansen 1940). Foram confeccionadas lâminas permanentes utilizando-se o emblocamento em glicolmetacrilato (GMA) JB4 (Polysciences. Inc.), de acordo com as especificações do fabricante e de Feder \& O'Brien (1968).

Para a microscopia eletrônica de varredura as amostras passaram por desidratação em série alcoólico etílica e, posteriormente, via ponto crítico em aparelho Balzers CPC 010 (Silveira 1989). Em seguida foram coladas com esmalte incolor e grafite em suporte próprio. A metalização, em ouro, foi efetuada em equipamento Balzers Sputtering SCD 030.

As fotomicrografias foram realizadas em fotomicroscópio ZEISS. As eletromicrografias foram realizadas em microscópio eletrônico de varredura SEM 505 Philips.

\section{Resultados e Discussão}

\section{Axonopus scoparius}

Lâmina foliar - As células da epiderme (figuras1-2) em vista frontal são organizadas em fileiras paralelas ao longo do eixo da folha, padrão típico de gramíneas (Metcalfe 1960, Esau 1976, Dahlgreen et al. 1985).
A epiderme da face adaxial, em vista frontal (figura 1), é constituída na zona intercostal por células longas, de forma retangular, levemente sinuosas, justapostas, alternando-se, às vezes, com células curtas que variam em comprimento e largura, normalmente contendo corpos silicosos em forma de cruz ou halteres como os descritos para Poaceae por Metcalfe (1960), Silva \& Laboriau (1970), Dahlgreen et al. (1985) e Fahn (1990).

Tricomas tectores (figura 1), unicelulares, longos, retos, com paredes espessas e extremidades afiladas aparecem distribuídos na zona intercostal e somente na face adaxial, semelhantes aos descritos por Metcalfe (1960) e Gould (1968).

$\mathrm{Na}$ zona costal, da face adaxial, evidenciam-se muitas células curtas contendo corpos silicosos em forma de halteres.

Os estômatos são raros na face adaxial e abundantes na face abaxial, como citado por Anton (1986). A folha caracteriza-se como anfihipoestomática, conforme menciona Napp-Zinn (1973). O complexo estomático (figura 2) é constituído por duas células guardas em forma de halteres e por um par de células subsidiárias de forma triangular, típica de várias gramíneas (Metcalfe 1960, Milby 1971, Esau 1976, Fahn 1990).

Tomlinson (1974), classifica os estômatos de gramíneas como tetracítico, porém preferiu-se adotar a classificação de Metcalfe (1960), que utiliza as diferentes formas das células subsidiárias para classificá-los. Na espécie em questão, os estômatos se enquadram no grupo com células subsidiárias triangulares. Essa classificação foi também adotada por Gould (1968) e Monteiro \& Pace (1984).

A zona intercostal, da face abaxial, contém corpos silicosos em forma de cruz e tricomas, curtos, bicelulares com a célula proximal menor que a distal (figura 3), sendo esta última afilada no ápice, como constatado por Metcalfe (1960), Gould (1968), Dahlgreen et al. (1985). A presença de tricomas curtos, bicelulares, também é característica marcante da subfamília Panicoideae (Gould 1968). Na zona costal (figura 2) aparecem muitas células curtas e corpos silicosos em forma de halteres ou em cruz.

A epiderme da face abaxial em secção transversal (figura 4) difere da face adaxial devido às células serem menores e apresentarem parede periclinal externa lignificada.

Metcalfe (1960) divide a lâmina foliar, quando em secção transversal, em duas regiões: a região da nervura central, designada quilha foliar, e a região restante, designada limbo foliar (asas). O mesofilo (figura 4) é 

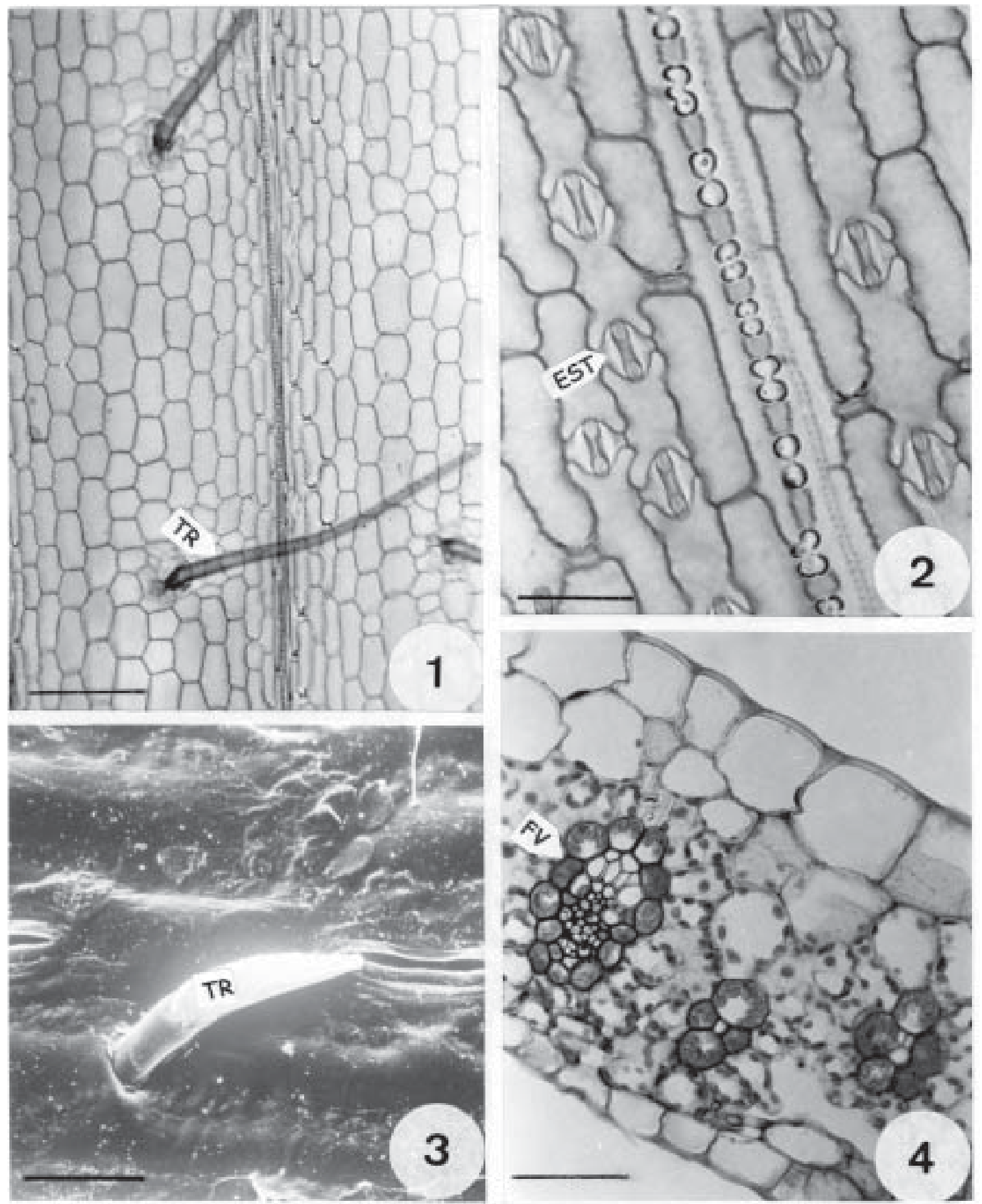

Figuras 1-4. Axonopus scoparius - lâmina foliar. 1. Epiderme em vista frontal da face adaxial. Barra $=50 \mu \mathrm{m} .2$. Epiderme, vista frontal da face abaxial. Barra $=100 \mu \mathrm{m}$. 3. Tricoma bicelular da face abaxial da epiderme em eletromicrografia de varredura. Barra $=10 \mu \mathrm{m}$. 4. Secção transversal da lâmina foliar com estrutura Kranz e feixes vasculares de três tamanhos. Barra $=100 \mu \mathrm{m} . \mathrm{TR}=$ Tricoma, EST $=$ Estômato, $\mathrm{FV}=$ Feixe vascular.

Figures 1-4. Axonopus scoparius - foliar blade. 1. Epidermis in frontal view of adaxial face. Bar $=50 \mu \mathrm{m}$. 2. Epidermis, frontal view of adaxial face. Bar $=100 \mu \mathrm{m}$. 3. Scanning electron micrograph of bicellular trichomes from abaxial epidermis. Bar $=10 \mu \mathrm{m}$. 4. Transverse section of foliar blade with Kranz structure and three vascular bundle sizes. Bar $=100 \mu \mathrm{m}$. TR $=$ Trichomes, EST $=$ Stomata, FV = Vascular bundle. 
composto por clorênquima e por um estrato de células, geralmente, desprovidas de cloroplastídeos, localizado próximo à face adaxial, sendo que as células que circundam os feixes vasculares apresentam disposição radiada.

As nervuras apresentam feixes vasculares colaterais de pequeno, médio e grande porte. Em secção transversal, os feixes vasculares de grande porte (figura 5) contêm dois grandes vasos do metaxilema lateralmente ao protoxilema. O floema acha-se circundado por fibras. Uma bainha parenquimática circunda parcialmente o feixe, sendo interrompida por células esclerenquimáticas próximas ao floema. Característica similar foi descrita por Monteiro \& Pace (1984). Essa bainha é constituída por células de paredes lignificadas, contendo cloroplastos grandes em posição centrífuga. De acordo com Dengler et al. (1985), essa bainha é conhecida como bainha Kranz ou bainha PCR (células de assimilação fotossintética do carbono). Essa característica, aliada à disposição radiada das células do mesofilo, é considerada como estrutura Kranz e descrita por Haberlandt (1928). A estrutura Kranz está associada freqüentemente ao processo fotossintético $\mathrm{C}_{4}$. Oliveira et al. (1973) afirmam que a espécie A. scoparius apresenta via fotossintética $\mathrm{C}_{4}$, estando em concordância com as afirmações de Carolin et al. (1973), de que a bainha do feixe tipo panicóide (bainha simples) ocorre em gramíneas com processo fotossintético $\mathrm{C}_{4}$.

Anton (1986) não incluiu A. scoparius entre as espécies que podem realizar o processo fotossintético $\mathrm{C}_{4}$, conseqüentemente, com estrutura Kranz, como aqui apresentado.

Ligados à bainha do feixe de grande porte encontram-se cordões de esclerênquima em contato com ambas as faces da epiderme, como os mencionados por Metcalfe (1960) e Gould (1968). Esses cordões de esclerênquima têm sido designados por Mauseth (1988) como extensão de bainha do feixe vascular.

Os feixes vasculares de médio porte não apresentam protoxilema e metaxilema distintos (figura 4). Esses feixes são circundados totalmente pela bainha Kranz, com células pouco lignificadas. A extensão de bainha aparece freqüentemente na face abaxial e, ocasionalmente, na face adaxial.

Os feixes vasculares de pequeno porte ocasionalmente apresentam floema e xilema distintos, freqüentemente, pode-se distinguir apenas o xilema (figura 4). Também são circundados totalmente pela bainha Kranz e, ocasionalmente, podem apresentar extensão de bainha na face abaxial.
A quilha foliar apresenta forma triangular quando vista em secção transversal. Células desprovidas de cloroplastídeos, com paredes delgadas, se encontram na região subepidérmica da face adaxial e preenchem o centro da quilha. Os feixes vasculares de pequeno, médio e grande portes, localizam-se próximo à face abaxial, juntamente ao clorênquima. $\mathrm{O}$ feixe vascular central destaca-se por apresentar a extensão de bainha esclerenquimática na face abaxial, mais desenvolvida que a dos outros feixes vasculares.

Bainha foliar - As células da face abaxial da epiderme apresentam sinuosidade muito mais elevada do que na lâmina foliar. Destaca-se a presença de um elevado número de corpos silicosos em forma de cruz nesta mesma face (figura 6). Já o mesofilo (figura 7) consiste de células com paredes delgadas, sendo a maioria desprovida de pigmentos. Aerênquimas são encontrados entre os feixes vasculares intercalados por diafragmas.

Os diafragmas são formados por células braciformes (figura 7), semelhantes às descritas por Haberlandt (1928), Kaul (1976), Esau (1985), Cutter (1986) e Fahn (1990). Em geral, esses diafragmas dividem transversalmente os canais longitudinais que constituem as lacunas, como na bainha de Musa rosacea (Musaceae) descrita por Alquini (1992) e em folhas de plantas aquáticas, como Hydrocleis nymphoides (Limnocharitaceae) e Limnobium laevigatum (Hydrocharitaceae), ambas descritas por Bona \& Alquini (1995a, b). Na bainha de A. scoparius, os diafragmas apresentam-se dividindo irregularmente os canais longitudinais, dificultando a visualização desses septos nas secções transversais.

Monteiro \& Pace (1984), ao descreverem a bainha foliar de Axonopus compressus, mencionam a presença de lacunas lisígenas, onde se evidenciam células ramificadas de clorênquima, próximo às nervuras. Certamente trata-se da mesma característica observada em A. scoparius, supramencionada.

Os feixes vasculares são circundados por uma bainha de células com paredes lignificadas com extensão que pode ir até a face abaxial ou ser interrompida por células constituintes do mesofilo e formarem calotas de esclerênquima na face abaxial. As células dessa bainha na região do xilema geralmente apresentam cloroplastos, porém em pequena proporção. Caule - Em secção transversal, o caule (figura 8) apresenta estrutura atactostélica como citado por Esau (1985), Cutter (1986), Gifford \& Foster (1988) e Mauseth (1988). O mesmo revela um estrato unisseriado de células epidérmicas, justapostas com paredes lignificadas em toda a extensão. Posteriormente, 

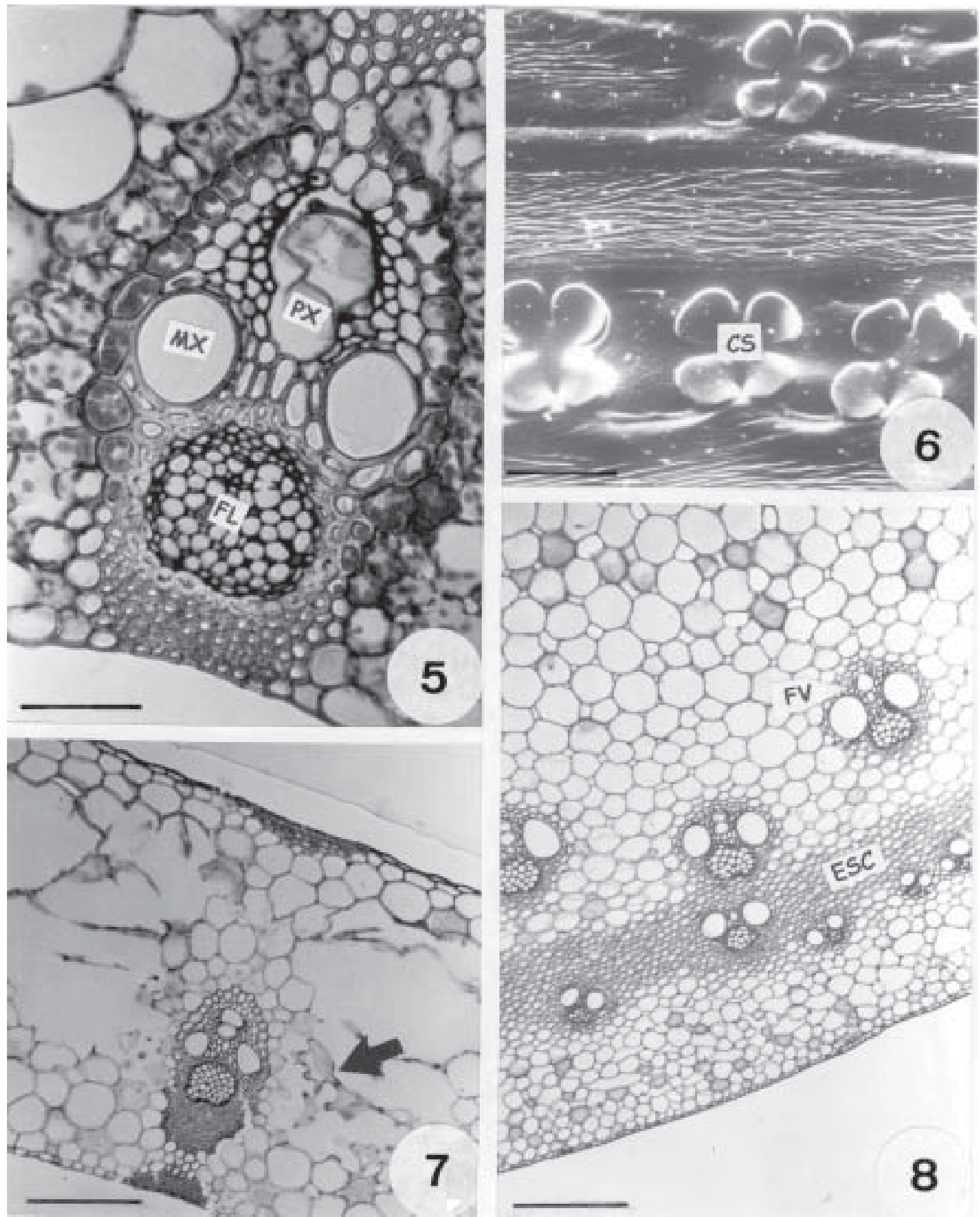

Figuras 5-8. Axonopus scoparius. 5. Feixe vascular de grande porte da lâmina foliar. Barra $=100 \mu \mathrm{m}$. 6. Corpos silicosos em forma de cruz na epiderme abaxial da bainha foliar em eletromicrografia. Barra $=10 \mu \mathrm{m}$. 7. Bainha foliar em secção transversal. Células braciformes do diafragma (seta). Barra $=50 \mu \mathrm{m}$. 8. Caule em secção transversal. Barra $=50 \mu \mathrm{m}$. PX $=$ Protoxilema, $M X=$ Metaxilema, $\mathrm{FL}=$ Floema, $\mathrm{CS}=$ Corpo silicoso, $\mathrm{FV}=$ Feixe vascular, $\mathrm{ESC}=$ Esclerênquima.

Figures 5-8. Axonopus scoparius. 5. Large vascular bundle of foliar blade. Bar $=100 \mu \mathrm{m}$. 6. Scanning electron micrograph of cross-shaped silica-bodies, on epidermis of foliar blade. Bar $=10 \mu \mathrm{m}$. 7. Transverse section of foliar blade. Braciform cells from diafragm (arrow). Bar $=50 \mu \mathrm{m}$. 8. Transverse section of the stem. Bar $=50 \mu \mathrm{m} . \mathrm{PX}=$ Protoxylem. $\mathrm{MX}=$ Metaxylem, $\mathrm{FL}=\mathrm{Phloem}$, $\mathrm{CS}=$ Silica-bodies, $\mathrm{FV}=$ Vascular bundle, $\mathrm{ESC}=$ Sclerenchyma . 
evidencia-se o clorênquima, que é constituído de aproximadamente oito estratos de células com paredes delgadas. Ocasionalmente, evidenciam-se algumas células com paredes lignificadas. Pequenos espaços intercelulares e feixes vasculares de pequeno porte podem ser encontrados nessa região. Esses feixes vasculares são circundados por uma bainha de células com paredes lignificadas.

Internamente ao clorênquima evidencia-se um anel esclerenquimático, onde encontram-se inclusos feixes vasculares de médio e grande porte. Ambos os feixes apresentam proto e metaxilema, porém nos feixes de grande porte, os elementos do protoxilema aparecem desintegrados, freqüentemente, constituindo uma lacuna ou canal do protoxilema, como mencionado por Gould (1968), Cutter (1986) e Fahn (1990). Esses feixes são circundados por uma bainha de células com paredes lignificadas, semelhante à bainha esclerenquimática referenciada por Metcalfe (1960), Esau (1985), Cutter (1986) e Fahn (1990).

O parênquima fundamental ocupa toda a região central do caule. Suas células possuem paredes delgadas, são desprovidas de pigmentos e apresentam entre si pequenos espaços intercelulares. Feixes de grande porte podem ser evidenciados nessa região.

\section{Axonopus fissifolius}

Essa espécie, sendo do mesmo gênero que a anteriormente descrita, apresenta grande parte das características similares, diferindo em apenas alguns aspectos. Ao final dos comentários apresenta-se um quadro comparativo entre as espécies (tabela 1).

A lâmina foliar apresenta a nervura central com aspecto triangular, quando em secção transversal (figura 9). A epiderme da face adaxial da lâmina foliar, em vista frontal revela as mesmas características da face abaxial contando com a presença de células longas e curtas, de paredes sinuosas, corpos silicosos em formato de halteres e de cruz e tricomas curtos bicelulares. Os estômatos com células subsidiárias triangulares, encontram-se em quantidade proporcionalmente similar em ambas as faces da epiderme, caracterizando a folha como anfiestomática, como menciona Napp-Zinn (1973).

As evidências anatômicas da estrutura Kranz indicam que A. fissifolius deve apresentar o processo fotossintético $\mathrm{C}_{4}$, tal qual menciona Anton (1986 ).

Células buliformes (figura 10), maiores que as células típicas da epiderme e com paredes delgadas, como as citadas por Metcalfe (1960), Esau (1976), Buvat (1989), Mauseth (1988) e Fahn (1990) podem ser evidenciadas na epiderme da face adaxial, formando faixas isoladas entre os feixes vasculares e, freqüentemente, ocupando toda a face adaxial na região da quilha.

Em secção transversal, a bainha foliar apresenta, na epiderme adaxial, calotas esclerenquimáticas na região dos feixes vasculares. Entre os feixes vasculares ocorrem lacunas constituídas por canais longitudinais contendo diafragmas com células braciformes (figura 11).

$\mathrm{O}$ aspecto marcadamente sinuoso das células longas da epiderme pode ser evidenciado na face abaxial da bainha foliar, em vista frontal (figura 12).

O caule, em secção transversal (figura 13), revela epiderme unisseriada com células altamente lignificadas em toda a extensão. O anel esclerenquimático, situa-se a aproximadamente doze estratos celulares da epiderme. Os feixes vasculares são de pequeno, médio e grande portes.

Tabela 1. Comparação distintiva das características anatômicas de Axonopus scoparius e Axonopus fissifolius.

Table 1. Comparative analysis of anatomic characters between Axonopus scoparius and Axonopus fissifolius.

\begin{tabular}{lll}
\hline Estrutura & Axonopus scoparius & Axonopus fissifolius \\
\hline $\begin{array}{l}\text { Folha } \\
\begin{array}{l}\text { Tricomas longos, unicelulares na } \\
\text { epiderme da face adaxial da lâmi- } \\
\text { na foliar }\end{array}\end{array}$ & $\begin{array}{l}\text { anfihipoestomática } \\
\text { presentes }\end{array}$ & $\begin{array}{l}\text { anfiestomática } \\
\text { ausentes }\end{array}$ \\
$\begin{array}{l}\text { Tricomas curtos, bicelulares na } \\
\text { epiderme da lâmina foliar }\end{array}$ & Presentes somente na face abaxial \\
$\begin{array}{l}\text { Células buliformes da face adaxial } \\
\text { Esclerênquima (localização) }\end{array}$ & Presentes em ambas as faces \\
\hline
\end{tabular}




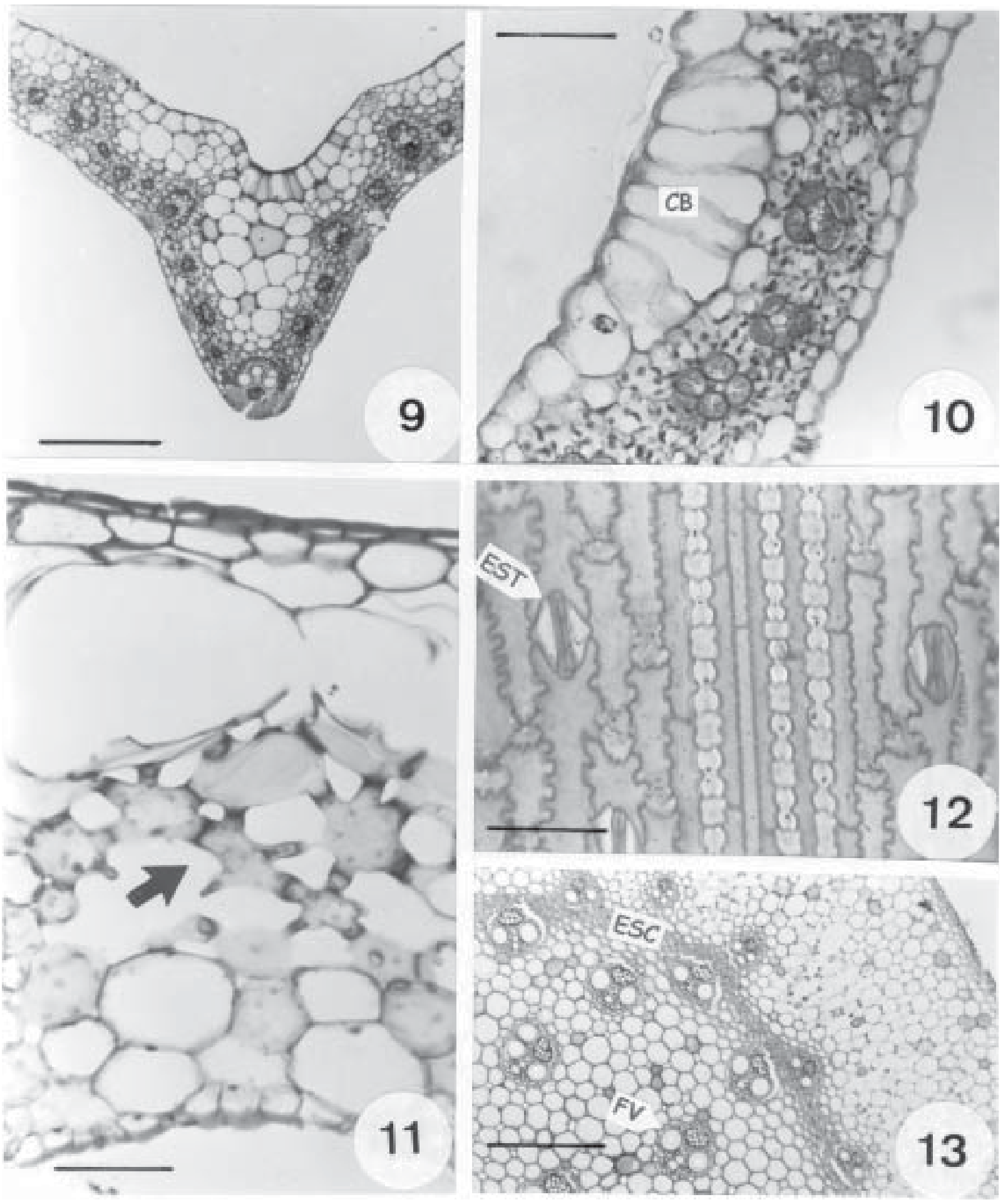

Figuras 9-13. Axonopus fissifolius. 9. Quilha foliar em secção transversal. Barra $=50 \mu \mathrm{m}$. 10. Limbo foliar em secção transversal. Barra $=100 \mu \mathrm{m}$. 11. Bainha foliar em secção transversal. Células braciformes (seta). Barra $=100 \mu \mathrm{m}$. 12. Epiderme da bainha foliar em vista frontal da face abaxial. Barra $=100 \mu \mathrm{m}$. 13. Caule, em secção transversal. Barra $=50 \mu \mathrm{m} . \mathrm{CB}=\mathrm{C}$ Ćlulas buliformes, $\mathrm{EST}=$ Estômato, $\mathrm{ESC}=$ Esclerênquima, $\mathrm{FV}=$ Feixe vascular .

Figures 9-13. Axonopus fissifolius. 9. Foliar keel in transverse section. Bar $=50 \mu \mathrm{m}$. 10. Transverse section of foliar blade. Bar $=100 \mu \mathrm{m}$. 11. Sheaths in transverse section. Braciform cells (arrow). Bar $=100 \mu \mathrm{m}$. 12. Sheath epidermis in frontal view of abaxial face. Bar $=100 \mu \mathrm{m}$. 13. Stem in transverse section. $\mathrm{Bar}=50 \mu \mathrm{m} . \mathrm{CB}=$ Bulliform cells, EST $=$ Stomata, $\mathrm{ESC}=$ Sclerenchyma, $\mathrm{FV}=$ Vascular bundle. 


\section{Referências bibliográficas}

AKIN, D.E. 1979. Microscopic evaluation of forage digestion by rumen microrganisms: A review. Journal of Animal Science 48:701-709.

ALQUINI, Y. 1992. Anatomia dos órgãos em desenvolvimento de Musa rosacea (Musaceae). Tese de doutorado, Universidade de São Paulo, São Paulo.

ANTON, A.M. 1986. Contribuición al conocimento de la anatomia foliar del genero Axonopus (Poaceae). Darwiniana 27:157-168.

BONA, C. \& ALQUINI, Y. 1995a. Alguns aspectos estruturais da folha de Hydrocleis nymphoides (Humb. \& Bonpl. ex Willd.) Buchenau (Limnocharitaceae). Arquivos de Biologia e Tecnologia 38:869-877.

BONA, C. \& ALQUINI, Y. 1995b. Alguns aspectos estruturais da folha de Limnobium laevigatum (Humb. \& Bonpl. ex Willd.) Heine (Hydrocharitaceae). Arquivos de Biologia e Tecnologia 38:1045-1052.

BUVAT, R. 1989. Ontogeny cell differentiation and structural of vascular plants. Springer Verlag, Berlin.

CAROLIN, R.C., JACOBS, S.W.L. \& VESK, M. 1973. The structure of the cells of the mesophyll and parenchymatous bundle sheath of the Gramineae. Botanical Journal Linnean Society 66:259-275.

CUTTER, E. 1986. Anatomia vegetal: Parte I Células e tecidos. $2^{\mathrm{a}}$ ed. Roca, São Paulo.

DAHLGREEN, R.M.T., CLIFFORD, H.T. \& YEO, P.F. 1985. The families of the Monocotyledons: structure, evolution and taxonomy. Verlag Berlin Heidelberg, Berlin.

DEDECCA, D.M. 1956. As espécies brasileiras do gênero Axonopus (Gramineae). Bragantia 19:251-296.

DENGLER, N.G., DENGLER, R.E. \& HATTERSLEY, P.W. 1985. Differing ontogenetic origins of PCR (Kranz) sheaths in leaf blades of $\mathrm{C}_{4}$ grasses (POACEAE). American Journal of Botany 72:284-302.

DESCHAMPS, F.C. 1994. Degradabilidade ruminal da matéria seca e da proteína de alguns alimentos utilizáveis na alimentação de ruminantes. Revista da Sociedade Brasileira de Zootecnia 23:898-908.

ESAU, K. 1976. Anatomy of seed plants. $3^{\text {th }}$ ed. John Willey and Sons, New York.

ESAU, K. 1985. Anatomía vegetal. $3^{\text {a }}$ ed. Omega, Barcelona.

FAHN, A. 1990. Plant anatomy. $4^{\text {th }}$ ed. Pergamon Press, Oxford.

FEDER, N. \& O'BRIEN, T.P. 1968. Plant microthecnique some principles and new methods. American Journal of Botany 55:123-142.

GIFFORD, E.M. \& FOSTER, A.S. 1989. Morphology and evolution of vascular plants. W.H. Freeman \& Co., New York.
GOULD, F.W. 1968. Grass systematics. Mc Graw Hill Book, New York.

HABERLANDT, G. 1928. Physiological plant anatomy. Mc Millan, London.

JOHANSEN, D.A. 1940. Plant microtechnique. Mc Graw Hill Book, New York.

KAUL, R.B. 1976. Anatomical observation on floating leaves. Aquatic Botany 2:215-234.

MAUSETH, J.D. 1988. Plant anatomy. Benjanmin Cummings, California.

METCALFE, C.R. 1960. Anatomy of the Monocotyledons. Clarendon Press, Oxford.

MILBY, T.H. 1971.The leaf anatomy of Buffalo grass Buchloe dactyloides (Nutt) Engelm. Botanical Gazette 132:308-313.

MONTEIRO, M.C.C. \& PACE, L.B. 1984. Anatomia foliar de Axonopus compressus (Sw.) Beauv.-GRAM. Atas da Sociedade Botânica do Brasil 2:37-44.

NAPP-ZINN, K. 1973. Anatomie des Blattes. II Blattanatomie der Angiospermen. In Handbuch der Planzenanatomie (K. Linsbauer, ed.). Gebrüder Borntraeger, Berlin.

OLIVEIRA, A.B., FARIA, P.R.S., SOUTO, S.M., CARNEIRO, A.M., DOBEIREINER J. \& ARONOVICH, S. 1973. Identificação de gramíneas tropicais com via fotossintética $\mathrm{C}_{4}$ pela anatomia foliar. Pesquisa Agropecuária Brasileira 8:267-271.

REYNA, J.V. \& DAVILA, P.D. 1995. Classificación de los generos de las gramineas (Poaceae) mexicanas. Acta Botánica Mexicana 33:37-50.

RODELLA, R.A., AYOUB, J.F. \& MAIMONI-RODELLA, R.C.S. 1984. Estudo quantitativo de características anatômicas da folha de Panicum maximum Jacq. e Panicum coloratum L. Revista de Agricultura 59:163-174.

SILVA, S.T. \& LABORIAU, L.G. 1970. Corpos silicosos de gramíneas dos cerrados III. Pesquisa Agropecuária Brasileira 5:167-182.

SILVEIRA, M. 1989. Preparo de amostras biológicas para microscopia eletrônica de varredura. In Manual sobre técnicas básicas em microscopia eletrônica. v. 1 . (W. Souza, ed.). Sociedade Brasileira de Microscopia Eletrônica, Rio de Janeiro, p.71-79.

SMITH, L.B., WASSHANSEN, D.C. \& KLEIN, R.M. 1982. Gramíneas. In Flora ilustrada catarinense, I parte (R. Reitz, ed.). Herbário Barbosa Rodrigues, Itajaí, p.1127-1129.

TOMLINSON, P.B. 1974. Development of the stomatal complex as a taxonomic character in the Monocotyledons. Taxon 23:109-128. 